\title{
The Structure of Dubliners and Order of the Stories
}

The Sisters

An Encounter

Araby

stories of childhood

Eveline

After the Race

Two Gallants

The Boarding House

A Little Cloud

Counterparts

Clay

A Painful Case

Ivy Day in the Committee Room

A Mother

Grace

stories of public life

stories of maturity

The Dead 